\title{
Eddy current based, contactless position transducer for a gas handle
}

\author{
Alex Van den Bossche ${ }^{1}$, Peter Sergeant* ${ }^{1,2}$ \\ 1 Department of Electrical Energy, Systems and Automation, Ghent University \\ B-9000 Ghent, Belgium \\ Tel.: +32 (0) $92643419 \quad$ Fax: +32 (0) 92643582 . \\ E-Mail: Alex.VandenBossche@UGent.be \\ URL: www.eesa.ugent.be \\ 2 Dept. Electrotechnology, Faculty of Applied Engineering Sciences, University College Ghent, \\ B-9000 Ghent, Belgium, Peter.Sergeant@hogent.be
}

\begin{abstract}
In electric vehicles, it is normal to have an electronic set value for 'gas' and for 'brake'. Traditional potentiometers with sliding contacts are not reliable. Magnetoresistive sensors or hall effect sensors need a magnet on the moving part. The proposed sensor just needs iron on the moving part. It uses an oscillator circuit where the absorbed current is an indication of damping, so how close the iron is to the sensor. The component cost is low and the output has a soft gradual change with the displacement.
\end{abstract}

Keywords

Transducer, sensor, oscillator, electric vehicle, drive by wire

\section{INTRODUCTION}

Although the set values for the gas and brake are simple quantities, they can cause a lot of trouble if something goes wrong. Malfunction can have either an electronic or a mechanic reason. The design of the sensor was done without taking in account the news of troubles of the sticking gas pedal in Toyota cars [1].

The missing signals can cause a lot of troubles in design [2]. In other systems also transducers are required [3]. In this paper we think in applications of ultralight vehicles, where a simplification of the global design is required.

Inductive sensing does not require special materials on the moving side. A lot of inductive sensing is done in industry, but most of them are proximity switches and do not give a gradual output. When using inductive sensing, several principles can be used, always based on a resonant LCcircuit:

The moving part is a conductor like copper or aluminum, in which eddy currents are induced by the resonant LC-circuit. The resonance frequency increases when the conductor approaches the sensing coil.

The moving part is a low loss magnetic material like ferrite. In this case, the resonance frequency is reduced while approaching the sensing coil.

The moving part is a magnetic material with a lot of losses at high frequency like steel. The frequency decreases a little bit while approaching the sensing coil, but the coil is heavily damped.
If the moving part is zinc coated iron, the frequency increases or decreases, depending on the coating thickness, but the core is more heavily damped than a steel plate while approaching the sensing coil.

- $\quad$ Other metals like stainless steel behave somewhat in between

We did choose steel (without zinc coating) as it is easily available and not sensitive to the amount of metal coating, but it could be enameled or painted as a part of the magnetic air gap.

In some designs mainly the frequency change is used [4], in this paper we investigate what is possible using the change in losses.

\section{BASIC TWO TRANSISTOR SCHEME}

The sensing coil is put in an oscillator circuit. A possible version of the circuit is shown in fig. 1. It produces a sinusoidal voltage over the capacitance $\mathrm{C} 2$ and the sensing coil. The power consumption of that proposed oscillator circuit reflects the amount of damping.

The advantage is that no secondary winding at the sense coil is needed like in Hartley oscillators and no tap on the capacitor like in Colpitts oscillator [5]. The two transistor oscillator acts in class $\mathrm{C}$ : the transistor conducts a small part of the period. We had good experience using oscillators with two transistors [6]. They may contain bipolar transistors but also mosfets or junction fets can be used.

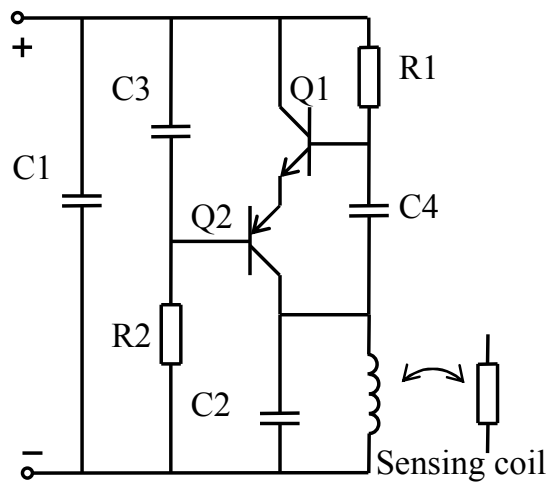

Fig.1. Two transistor oscillator scheme. 
The operating principle of the oscillator is the following:

In the scheme of Fig 2, C3 is rather a coupling capacitor, keeping the base of the transistor Q2 on a constant potential. $\mathrm{C} 4$ is the feedback capacitor. C4 is rather small, so that it acts as a capacitive divider with the base emitter capacitance of Q1.

If the damping is low, the voltage waveform over $\mathrm{C} 2$ is approximately a sine wave. Assume that the sinusoidal voltage over the coil is - at a given time instant - increasing, and that Q1 and Q2 are turned off. When the voltage over the coil nearly reaches the top of the sine wave, the transistor Q1 is turned on by $\mathrm{C} 4$. As the base of Q2 is at a constant potential, Q1 turns on transistor Q2 immediately. Now, the voltage over $\mathrm{C} 4$ starts to decrease as current flows to the base of Q1. After some time, the potential at the base of Q1 has decreased sufficiently to turn off $\mathrm{Q} 1$, and by consequence also Q2. The voltage over the coil decreases, and C4 charges again.

The resistors $\mathrm{R} 1$ and $\mathrm{R} 2$ provide some bias current for the transistors. R1 acts as a small phase lead circuit with $\mathrm{C} 4$. If a large bias current is given, the transistors will saturate and more distortion is visible.

There is a rectifying effect of the C-B junction of Q2, which lowers the voltage on $\mathrm{C} 3$. This regulates the oscillation amplitude.

The circuit can work well, but for a coil with a good Q-factor, the optimal bias current is low, whereas for a coil with a bad Q-factor a much higher bias current is required.

We observe that the current consumption at the supply is changing a lot when the coil is coupled with an object with eddy currents such as iron or a well conducting material.

\section{IMPROVED SCHEME FOR A HIGHER SENSITIVITY RANGE}

The two transistor scheme of Fig 1 is not good enough for a change in Q-factor in the range of a factor 20. We observed that a variable bias current was useful. This was obtained by adding a third transistor in order to regulate the bias current depending on the current consumption of the supply: see the scheme of Fig. 2. If the oscillator consumes more current because of damping by a metal plate in its proximity, the voltage over R4 increases. By consequence, transistor Q3 will conduct more current. This current is the bias current for transistor Q2. In other words, if the DC supply current is larger, also a larger bias current is given. A suitable choice of resistor R3 allows to adjust the bias current in such a way that the sensitivity range of the sensor is extended. This allows a very large change in Q-factor of the coil, without problems in the oscillator. Very low Q-factors do result in a behavior,

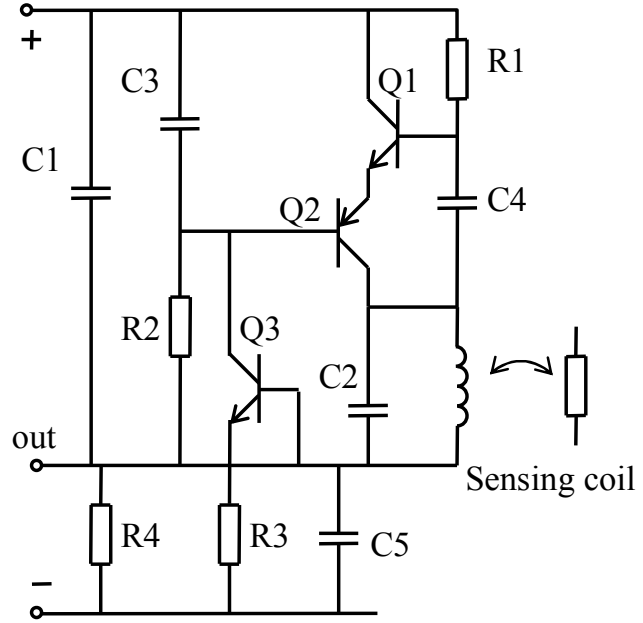

Fig. 2. Improved three transistor oscillator

which is close to a zero voltage switch resonant converter, rather than a class $\mathrm{C}$ oscillator.

In the experimental circuit, the resonance capacitor $\mathrm{C} 2$ was a low loss type of $100 \mathrm{pF}$.

The used inductor was a half RM7 ferrite core, consisting of 150 turns of $\mathrm{Cu} 0.16 \mathrm{~mm}$ copper wire on a half RM7 with hole. The high number of turns was chosen to obtain low eddy current losses in the copper wire, a low current consumption and a low induced field.

\section{MEASUREMENTS}

First a circuit was made using normal, trough hole components. The circuit was adapted until a large passive component value immunity was obtained and until the right topology was found. Afterwards the circuit was built in SMD (Surface Mounted Devices), where it seemed to behave in almost exactly the same way. So the sensitivity to the exact type of transistor is also low. The circuit does not contain much temperature sensitive elements. This high temperature robustness is a required feature for electronic equipment in vehicles. The circuit is designed to operate from a $12 \mathrm{~V}$ stabilized voltage.

Fig 3 shows a voltage waveform without load. The waveform is almost perfectly sinusoidal.

Fig 4 shows a waveform, where the inductor is loaded with an iron plate of $1.5 \mathrm{~mm}$ thickness at $0 \mathrm{~mm}$ distance. The penetration depth is rather 20 micrometer, so the thickness is not really relevant.

Further on, some output voltage measurements are shown to give an impression of the transfer characteristic. It is clear that the sensor is best placed close to the pivoting point. It is gradual at low current, which is also a useful behavior for a vehicle sensor. 


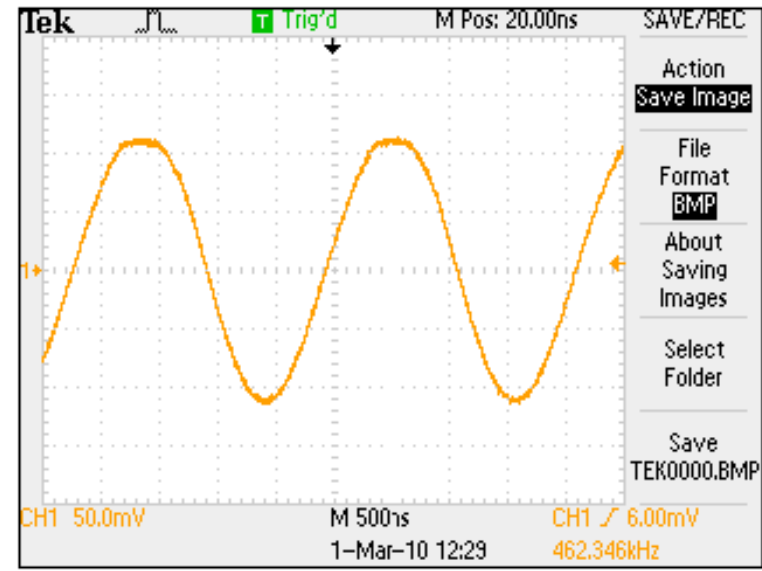

Fig. 3 No load voltage at the collector of Q2 compared to the negative supply, Horizontal: $0.5 \mu \mathrm{s} / \mathrm{div}$, Vertical:5V/div (100:1 probe)

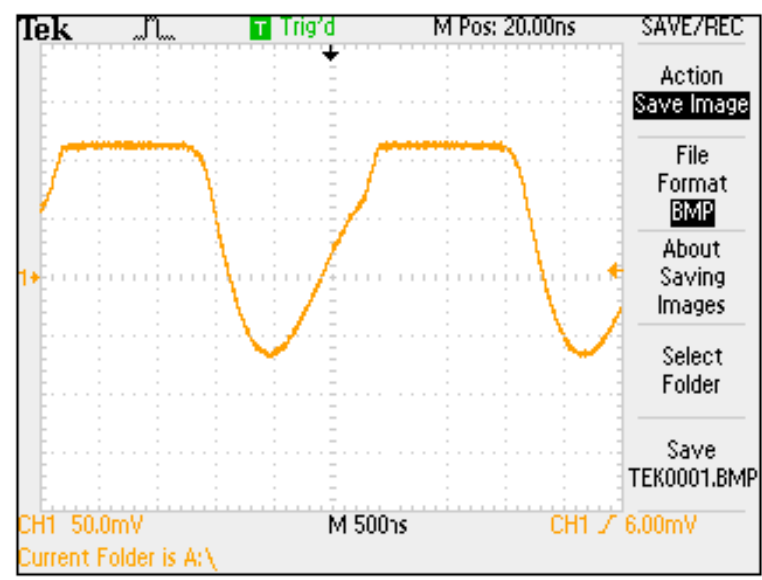

Fig. 4 Load voltage at the collector of Q2 compared to the negative supply Horizontal:0.5 $\mu \mathrm{s} / \mathrm{div}$, Vertical:5V/div (100:1 probe)

The output voltage measurements in Fig. 5 have been fitted with an equation, resulting in about $4 \%$ maximum deviation in output voltage, with a, the distance coil to plate.

$$
\text { Fit }(a):=\frac{a+4.3}{0.95(a)^{2}+0.6 a+1}+0.45
$$

Also an experiment is carried out where the plate makes an angle with the core, resulting in a characteristic of Fig. 6 .

The angle of the plate has been estimated by the opposite length of a right angle triangle (length $a_{m}$ ).

$$
\alpha_{\mathrm{m}}:=\operatorname{atan}\left(\frac{a_{\mathrm{m}}}{20}\right)
$$

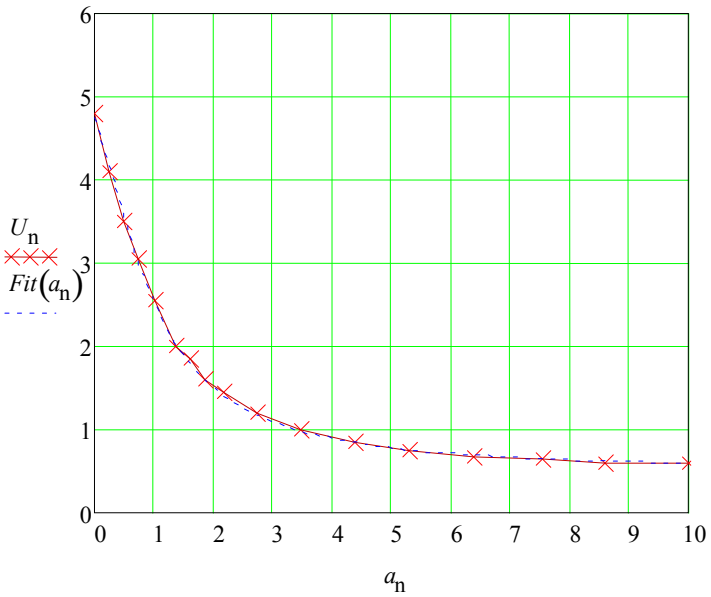

Fig 5. Output voltage as function of an iron plate distance in $\mathrm{mm}$

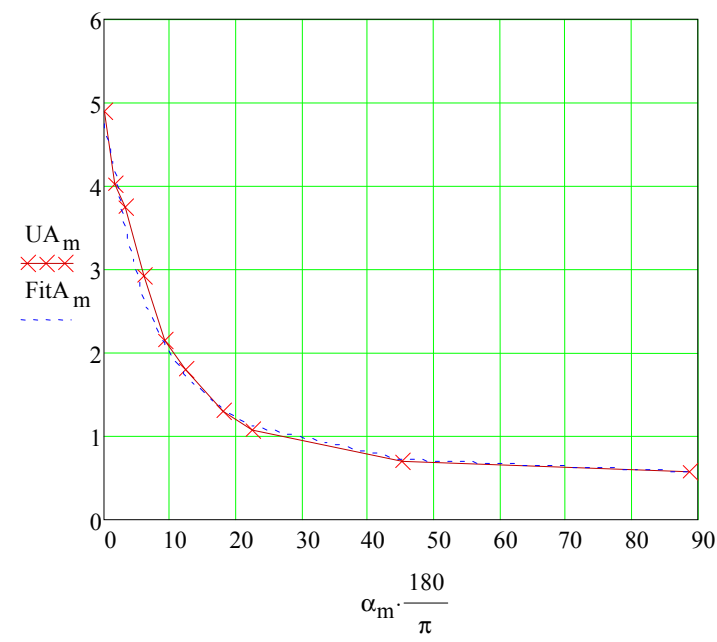

Fig. 6 Output voltage if the plate touches one side with an angle to the sensor.

A fit equation taking the winding distances distances at $50 \%$ of the radius in account.

$$
\text { Fit }_{\mathrm{m}}:=\frac{\text { Fit }\left(a_{\mathrm{m}} \cdot 0.25\right)+\text { Fit }\left(a_{\mathrm{m}} \cdot 0.75\right)}{2}
$$

So, in practice, the transducer may be used in a range from $1.0 \mathrm{~V}$ to $4.0 \mathrm{~V}$ output at $12 \mathrm{~V}$ input. Slightly different outputs can be obtained while using different component values. An open circuit in the coil results in zero output and a short circuit in the coil in about $9.5 \mathrm{~V}$. So those situations can be recognized.

Also other materials have been tried out: see table 1 . The zinc plated steel shows a higher output and a lower frequency shift. 
Note that the change in output voltage (or resonant circuit damping) is much more significant than the change in frequency.

TABLE I

OVERVIEW OF MATERIALS

\begin{tabular}{|l|l|l|l|l|l|}
\hline Material & Steel & $\begin{array}{l}\text { Zinc } \\
\text { plated } \\
\text { steel }\end{array}$ & $\begin{array}{l}\mathrm{Cu}, \\
35 \mu \mathrm{m}\end{array}$ & $\begin{array}{l}\mathrm{Cu}, \\
500 \mu \mathrm{m}\end{array}$ & $\begin{array}{l}\text { Alu13 } \mu \mathrm{m} \\
+ \text { steel }\end{array}$ \\
\hline $\begin{array}{l}\text { Freq open } \\
{[\mathrm{kHz}]}\end{array}$ & 440 & 440 & 440 & 440 & 440 \\
\hline $\begin{array}{l}\text { Freq closed } \\
{[\mathrm{kHz}]}\end{array}$ & 355 & 374 & 612 & 630 & 550 \\
\hline $\begin{array}{l}\text { Voltage open } \\
{[\mathrm{V}]}\end{array}$ & 0.57 & 0.57 & 0.57 & 0.57 & 0.57 \\
\hline $\begin{array}{l}\text { Voltage } \\
\text { closed [V] }\end{array}$ & 4.85 & 5.47 & 3.50 & 2.60 & 5.15 \\
\hline
\end{tabular}

The penetration depth of copper at that frequency is about $100 \mu \mathrm{m}$ [7]. The thin copper is thinner than the penetration depth at that frequency whereas the thick copper plate is thicker than the penetration depth.

The aluminum foil wit iron results in a nice output, but it is considered to be too fragile.

The frequency behavior changes a lot with the type of material, but the loss behavior goes usually in the same direction. Often only the frequency is measured and then an frequency demodulator is needed [4].
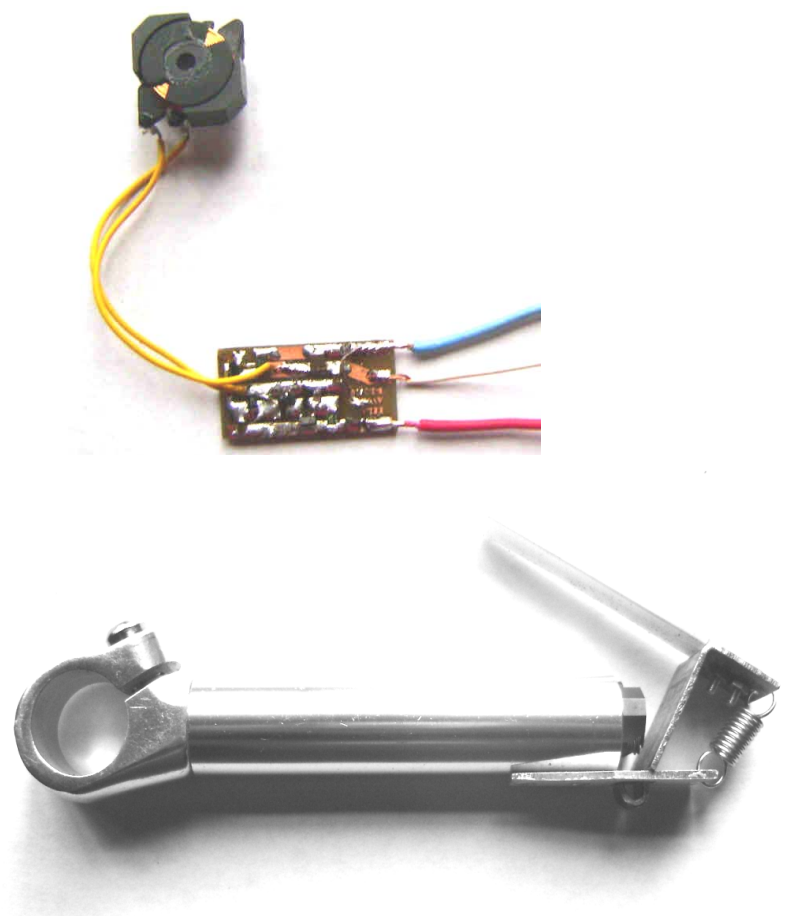

Fig. 7 Core and SMD circuit (upper) and build in inside the a $22.2 \mathrm{~mm}$ tube with handle (lower)

Fig 7a shows the SMD circuit before mounting in. The SMD experimental circuit itself is $15 \mathrm{~mm}$ by $28 \mathrm{~mm}$, and could be still reduced in size if required. Fig 7 shows it mounted in a handle of $22.2 \mathrm{~mm}$ tube diameter. Only the side of the core is visible outside the tube. A pivoting point is used as well as a spring for the 'zero current' position, an iron plate moves towards the core if the handle is pressed.

The transducer can be used for a gas as well as a brake handle (energy recuperation).

In the motor control, brake signals override gas signals.

In a gas foot pedal, there would be even more space for mounting than in a gas handle.

The EMC signature is low, as a high number of turns results in low currents and in a low induced emf, Also the wires are not carrying HF or digital signals.

\section{CONCLUSION}

The proposed eddy current iron loss sensor is a candidate for gas and brake handles in electric actuated vehicles. It is contactless and uses very common materials and components. It also can have a large operating temperature. As it based on an oscillator current consumption, it needs no demodulation or amplifier to operate.

\section{ACKNOWLEDGMENT}

The work was done at Ghent University, in the frame of a joint research supported by the Research Fund of University College Ghent (Hogeschool Gent). The research concerns ultralight vehicles with a codename "elbev" (ecologic, low budget electric vehicles).

\section{REFERENCES}

[1] http://pressroom.toyota.com/pr/tms/toyota/toyota-consumer-safetyadvisory-102572.aspx

[2] R. Hoseinnezhad, A. Bab-Hadiashar, Missing data compensation for safety-critical components in a drive-by wire system (2005), IEEE transactions on Vehicular Technology, Volume 54, Issue 4, pp. 13041311

[3] E. Christopher, A. B. Borrino-Bird, J.T. Chernoff et al, Drive by wire control input device for drive-by-wire system, US patent 7,509,195 Mar 24,2009.

[4] S. D. Roach, designing and building an eddy current position sensor, Sensors vol 15, No 9, 1998.

[5] P. Horowitz The art of Electronics, , Winfield Hill, 2001,ISBN 052137095 p298

[6] A. P. Van den Bossche, K. De Gussemé, V. C. Valchev, S. T. Barudov, Self-oscillating sine wave oscillator for ferrite loss measurements, EPE Dresden, 11-14 Sept 2005

[7] A. P. Van den Bossche, V. C. Valchev, Inductors and Transformers for Power Electronics, February 23, 2005, CRC-press, Boca Raton USA, ISBN 1574446797, hardcover, 480 pages. 